\title{
Deep Phenotyping of Development, Communication and Behaviour in Phelan-McDermid Syndrome
}

\author{
Gilles Droogmans $^{a}$ Ann Swillen ${ }^{a}$ b Griet Van Buggenhout ${ }^{a, b}$ \\ ${ }^{a}$ Department of Human Genetics, University of Leuven (KU Leuven), Leuven, Belgium; ${ }^{b}$ Centre for Human Genetics, \\ University Hospitals Leuven (UZ Leuven), Leuven, Belgium
}

\author{
Keywords \\ Autism · Behaviour - Communication - Development . \\ Genotype-phenotype correlation - Intellectual disability . \\ Phelan-McDermid syndrome · Regression · 22q13.3 \\ Deletion syndrome
}

\begin{abstract}
Phelan-McDermid syndrome (PMS; also referred to as 22 13.3 deletion syndrome) is a congenital condition due to a microdeletion in the SHANK3 gene. Cognitive and communicative deficits as well as behaviour in the autism spectrum are often noticed in affected individuals. The aim of the present study was to obtain a detailed phenotype of the development, communication, and behaviour of 15 individuals with PMS by using both quantitative (questionnaires) and qualitative methods (interviews and observations). In addition, data from the patients' medical records were included. In a subgroup of participants $(n=5)$, data from a previous study were incorporated to enable a comparison over 2 points in time (longitudinal course). Results indicate a severe to profound level of intellectual disability in all participants, impaired adaptive behaviour, a low level of speech and language, a high incidence of features of autism spectrum disorder (ASD), and a high sensory threshold. Younger individu-
\end{abstract}

\section{KARGER}

(C) 2019 S. Karger AG, Basel

E-Mail karger@karger.com

www.karger.com/msy als (age $<18$ years) exhibited more challenging behaviour and features of ASD. In older individuals with PMS, a regression across many developmental and adaptive domains was frequently reported and observed. We did not find a relation between the deletion size and the severity of the phenotype. Implications of the findings and recommendations for clinical practice and future research are discussed.

(c) 2019 S. Karger AG, Basel

Phelan-McDermid syndrome (PMS) is a rare, highly heterogeneous genetic disorder [Phelan and McDermid 2012]. The following 3 case vignettes illustrate the heterogeneity in the phenotypic expression of PMS.

\section{Case Reports}

Case 1

Jeremy is 12 years old and attends special needs education for children with a moderate to severe intellectual disability. His parents describe him as a sweet, active, and assertive child. Jeremy can exhibit challenging behaviour, such as getting angry because of a prohibition or running away from home. He has difficulties with

\section{A.S. and G.V.B. share senior authorship.}

Ann Swillen

Department of Human Genetics, University of Leuven

Herestraat 49

BE-3000 Leuven (Belgium)

E-Mail ann.swillen@ uzleuven.be 
transitions (such as a new teacher). He loves outdoor activities and can ride his go-cart or bicycle for hours. Jeremy is socially orientated; he will take initiative to communicate with others and enjoys these encounters. Jeremy's sentences are, however, telegraphic, and he frequently uses phonological processes to simplify speech. This makes it hard for strangers to understand him.

\section{Case 2}

Nicole is 35 years old. She lives with her parents and attends a day care centre for adults with a moderate to severe intellectual disability. Since her childhood she wears stockings because of lymphedema, and she regularly has infections. She is currently a calm and cheerful woman, but this present temperament is in contrast to the high level of activity during her childhood. Nowadays, she can spend hours in the sofa. She has forgotten how to spell her name and exhibits a shuffling gait as well as anxiety to take stairs (possibly because of impaired sight). Nicole likes things to be in the same place, e.g., she is very attentive that zippers are closed or that her mother's phone is put away in her purse. Nicole communicates using non-verbal signs, 2 distinct sounds, and the word "no". Her parents know each of her signals and understand their daughter very well.

\section{Case 3}

William is 54 years old and lives in a nursing home. His caregivers describe him as a person who likes to engage in social situations, but also as incomprehensible and changeable. Because of this unstable temperament and mood swings, he was diagnosed with bipolar disorder. William's behaviour fluctuates between being talkative, agitated or chaotic, and not talking, apathetic or suspicious. During the course of his life, a gradual loss of several domains was apparent: first, in 1997, after a hospitalisation for malignant neuroleptic syndrome and second, in 2004, after aspiration pneumonia and septic shock. In 1997, William had to re-acquire daily skills, and in 2004, he lost his motor and speech abilities. Also in 2004, lacunar infarcts were observed. Currently, William is wheelchair bound and expresses sounds similar to growling or moaning. His caregivers consider his expressed sounds as nonintentional.

Despite the heterogeneity, as is illustrated by the case reports above, several core characteristics can be distinguished. Individuals with PMS have moderate to severe intellectual disability (ID), delayed to absent speech, and show features of autism spectrum disorder (ASD) [Phelan et al., 2001; Havens et al., 2004; Manning et al., 2004; Cusmano-Ozog et al., 2007; Dhar et al., 2010; Shaw et al., 2011; Phelan and McDermid, 2012; Soorya et al., 2013; Zwanenburg et al., 2016]. There is a high incidence of psychiatric disorders such as attention deficit and hyperactivity disorder and bipolar disorder (BPD) [Shaw et al., 2011; Denayer et al., 2012]. Egger et al. [2016] suggested a PMS-specific atypical BPD that could be moderated with mood-stabilizing agents in combination with contextual measures based on the individual neuropsychological profile. Neonatal hypotonia is often the first presenting symptom in individuals with PMS and can contribute to poor feeding, speech difficulty, reduced reflexes, and delayed motor development [Phelan and McDermid, 2012]. Furthermore, seizures, structural brain abnormalities [e.g. the corpus callosum, Tabet et al., 2017], motor deficits, infections, and lymphedema as well as dental, vision, endocrine, renal, cardiac or gastrointestinal problems have been described [Phelan and Mc-
Dermid, 2012; Kolevzon et al., 2014]. Zwanenburg et al. [2016] observed no improvement in cognitive development over time, and Reierson et al. [2017] reported a regression in motor and self-help skills which is often apparent from mid-childhood. Regression may occur after acute events [Bonaglia et al., 2011; Denayer et al., 2012; Soorya et al., 2013; Serret et al., 2015; Egger et al., 2016].

A microdeletion of SHANK3 is likely responsible for the main features of PMS [Bonaglia et al., 2001; Wilson et al., 2003; Delhaye et al., 2009]. The gene is located at the terminal end of the long arm of chromosome 22 at position 13.3. The SHANK3 gene encodes a homonymous protein which acts as a scaffold in the postsynaptic density [Boeckers et al., 2002]. Deletion sizes tend to vary from 45.8$100 \mathrm{~kb}$ to 9-9.1 Mb [Luciani et al., 2003; Disciglio et al., 2014; Tabet et al., 2017]. Some studies report that larger deletion sizes are related to a more severe phenotype [Luciani et al., 2003; Wilson et al., 2003; Disciglio et al., 2014; Sarasua et al., 2014; Oberman et al., 2015; Zwanenburg et al., 2016], while others report that some individuals with small deletions can also be severely affected [Bonaglia et al., 2001; Delhaye et al., 2009; Misceo et al., 2011]. Specific genomic regions at $22 \mathrm{q} 13$ are thought to play a role in distinct features of the phenotype (e.g., absence of speech, ophthalmic features, gastroesophageal reflux, ASD, or neonatal hypotonia) [Sarasua et al., 2014; Oberman et al., 2015; Tabet et al., 2017]. In addition, Tabet et al. [2017] identified copy number variations (CNVs) at 16p11.2 and 15 q11q13 which could modulate the phenotypical severity of PMS.

The aim of the present study was to acquire detailed information on the development, communication, and behaviour of individuals with PMS. Size of the deletion, age group (young individuals $<18$ years and adults $>18$ years), and gender were also taken into account. In addition, in a subgroup of 5 individuals, previous cognitive and behavioural data were available [Denayer et al., 2012], allowing a comparison of these data between 2 points in time (longitudinal data).

\section{Materials and Methods}

\section{Study Population and Research Protocol}

All individuals with a confirmed diagnosis of 22q13.3 deletion syndrome (PMS) known at the Centre for Human Genetics (University Hospitals Leuven, Belgium) were invited to participate in the study $(N=18)$. The parents of the individuals were first contacted by phone, and the goal of the study and the study procedure were explained. If interested, a home visit was made. Questionnaires were handed over, and an interview was conducted. After the home visit, a direct observation of the individual with PMS was planned at the special education school or the institution for residential care. In case the participant with PMS needed full-time care in a residential home, the complete research procedure and protocol took place at the institution. Additionally, all medical records of the participants with PMS were studied to obtain data on the medical history, developmental milestones, and trajectory.

\section{Methods}

To assess the global development of the individuals with PMS, the Bayley Scales of Infant and Toddler Development (BSID-IIINL) [Bayley, 2015], Special Needs Addition was used. The BSIDIII-NL is an instrument to assess development between 2 and 42 months and 15 days; it is also used for older persons with a developmental age up to 42 months and 15 days. The Special Needs Ad- 
dition was chosen because of frequent hypotonia and difficulties with fine motor skills [Soorya et al., 2013]. The BSID-III-NL consists of 5 subscales: cognition, language comprehension and production, fine and gross motor function, social-emotional functioning, and adaptive behaviour [Van Baar et al., 2014]. For this study, only the cognitive subscale was used. Completion of the cognitive scale takes $30 \mathrm{~min}$, depending on the developmental age. If a recent assessment (last year) with the BSID-III-NL had taken place, these data were used for the analysis. Because of limited cooperation in some individuals, it was not possible to administer the BSID-IIINL cognitive scale in each person. Therefore, the Social and Life Skills scale (translated Sociale Redzaamheidsschaal; SRZ) was used for an estimation of the developmental level in addition to the available BSID-III-NL and developmental data.

Standardised questionnaires were used for the assessment of adaptive behaviour, communication level, emotional and behavioural problems, features of ASD, sensory information processing, and experienced life events.

SRZ is a standardised questionnaire to measure adaptive behaviour of people with ID [Kraijer and Kema, 1981]. SRZ is suitable for people with ID aged 7-40 years. SRZ comprises 4 domains: daily skills, language use, task orientation, and social orientation. Percentiles were calculated. Completion of the test takes 10-15 $\min$.

The Communication Profile of the Mentally Handicapped (translated CommunicatieProfiel Zwakzinnigen; CPZ) [Willems and Verpoorten, 1996] is a standardised instrument for determining the level of communication abilities in people with severe to profound ID. CPZ uses the final score of the SRZ test to select the norm group and is suitable for people with ID aged 7-40 years as well. It consists of a test and a questionnaire. Only the questionnaire was used in this study. CPZ is divided in 4 subscales: receptive non-vocal, receptive vocal, expressive non-vocal, and expressive vocal. Deciles were calculated for the 4 subscales. Completion of the CPZ questionnaire takes $45 \mathrm{~min}$.

The Developmental Behaviour Checklist (Dutch version, translated Vragenlijst voor Ontwikkeling en Gedrag; VOG) [Koot and Dekker, 2001] is a validated measure for the assessment of psychopathology in young people with ID (6-18 years). The questionnaire is completed by parents or daily caregivers. Each item is rated as $0=$ not at all, $1=$ a little or sometimes, or $2=$ clearly or very often. VOG comprises 5 subscales: disruptive, self-absorbed, communication disturbance, anxiety, and social relating. Percentiles were calculated. Completion of the VOG test takes approximately $15 \mathrm{~min}$.

The Autism and Related Disorders scale (translated Autisme en Verwante stoornissenschaal-Z-revisie; AVZ-R) is a screening measure for the assessment of ASD in people with ID aged 2-70 years [Kraijer, 1999]. It consists of 12 items that describe behaviour frequently observed in people with ASD. Four domains are analysed: contact with adults, contact with peers, language and speech, and other behaviour. This results in a final score which gives an indication of the likelihood of an ASD diagnosis. A score between 1 and 6 is classified as "normal," a score between 7 and 9 as "borderline," and a score higher than 10 is classified as "ASD." Completion of the AVZ-R screening takes 10-15 min.

The Short Sensory Profile (Dutch version) is a screening method to detect problems in sensory information processing [Dunn, 2013]. It can be used for individuals aged 4-12 years. Seven domains were analysed: tactile sensitivity, taste or smell sensitivity, movement sensitivity, under responsiveness or sensation seeking, auditory filtering, low energy or weakness, and visual or auditory sensitivity. Each item is scored with an indication of frequency (always, often, from time to time, rarely, or never). Completion of the Short Sensory Profile screening takes $15 \mathrm{~min}$.

The Questionnaire Experienced Events and their Impact (translated Vragenlijst Meegemaakte Gebeurtenissen en hun Impact; VMG-I) was used to examine events that happened during the person's lifespan. It is an adaptation of the Questionnaire Experienced Events (VMG; http://www.praktikon.nl/diensten/vragenlijsten/vmg/). Completion of VMG-I takes approximately 10 min. Due to limited available data, analysis of the VMG-I was not possible.

Besides the quantitative measures (questionnaires), 2 additional qualitative techniques were used to acquire detailed information on the phenotype of the participants with PMS. First, a semi-structured interview with parents and/or caregivers was taken. Topics during this interview were challenging behaviour and coping, progress and decline, and frustrations in communication. Second, the individual with PMS was observed in his/her natural setting (special education school or residential care) and recorded on video for approximately 1-2 $\mathrm{h}$. During the observation, extra focus was on contact/interaction, (verbal) communication and behaviour.

\section{Statistical Analyses}

The collected data were analysed using IBM SPSS Statistics 25. There were no missing values in the data set. The null-hypothesis was rejected when a $p$ value less than 0.05 (2-tailed exact significance level) was reached.

Because of the non-normal distribution of data, descriptive and non-parametric statistical methods were used. A Mann-Whitney test was performed to compare differences between 2 independent groups. A Kruskal-Wallis test was performed to compare differences between 3 or more independent groups. Wilcoxon signed rank tests were computed to test for differences between 2 related groups. Finally, for the assessment of an association between 2 categorical variables, Fisher exact test was used.

\section{Results}

Of the 18 potential subjects for the study, 15 persons with PMS participated (response rate of $83.33 \%$ ). Of the 15 participants, 6 were male and 9 female. Eight individuals were younger than 18 , seven were older than 18 years. The mean age was 22 years (SD 15.369, min. 4, max. 52), and all lived in Flanders (Belgium). All individuals $<18$ years, except Person 4 (P4) who received education by a special education teacher at home, attended a special education school for children with moderate to severe ID (87.5\%). Two adults (P12 and P14; 28.57\%) lived at home and attended a specialised day centre; the other $5(71.43 \%)$ needed full-time care in a residential home. None of the adults with PMS were able to work in a sheltered environment. Table 1 gives an overview of the demographic, ge- 


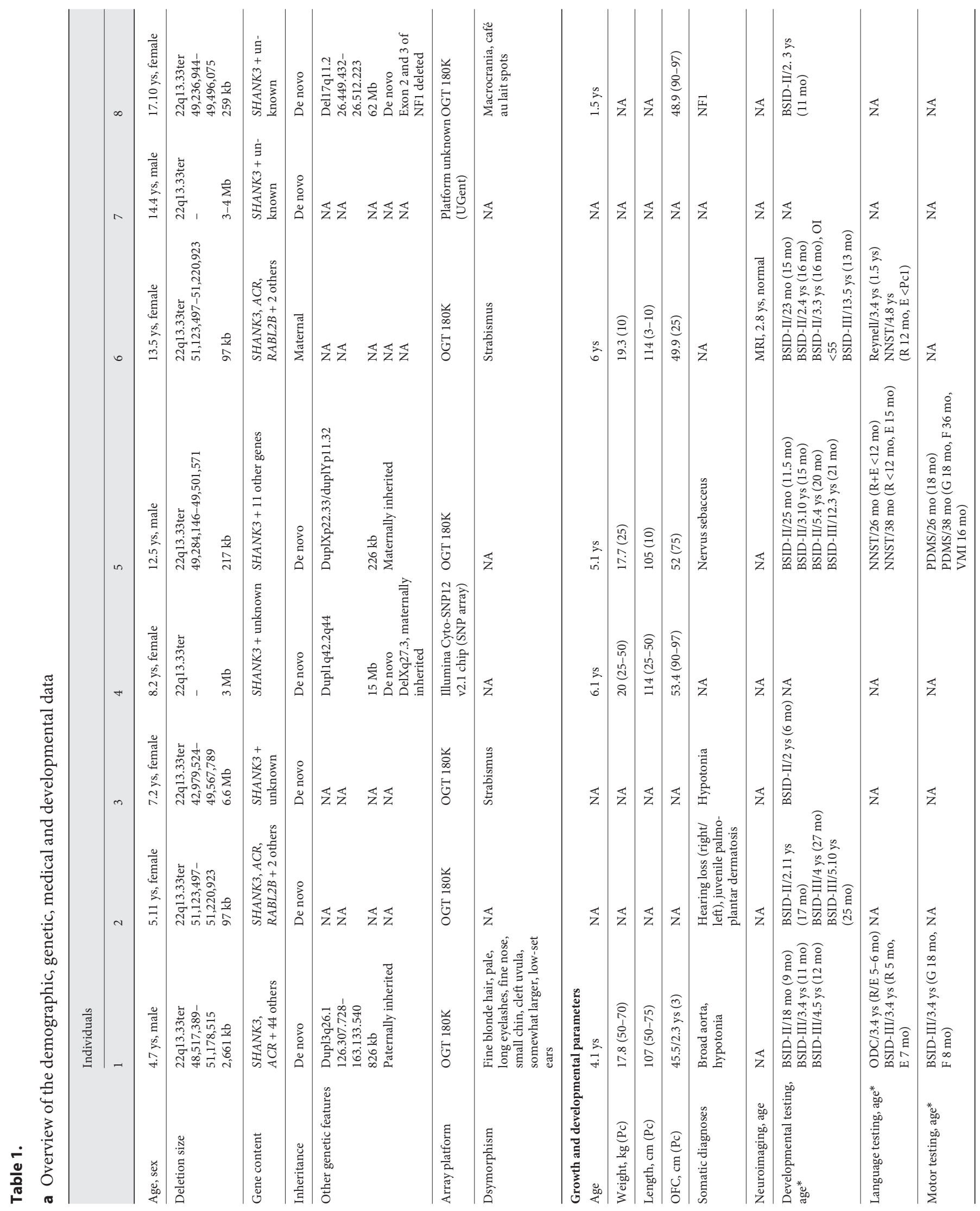




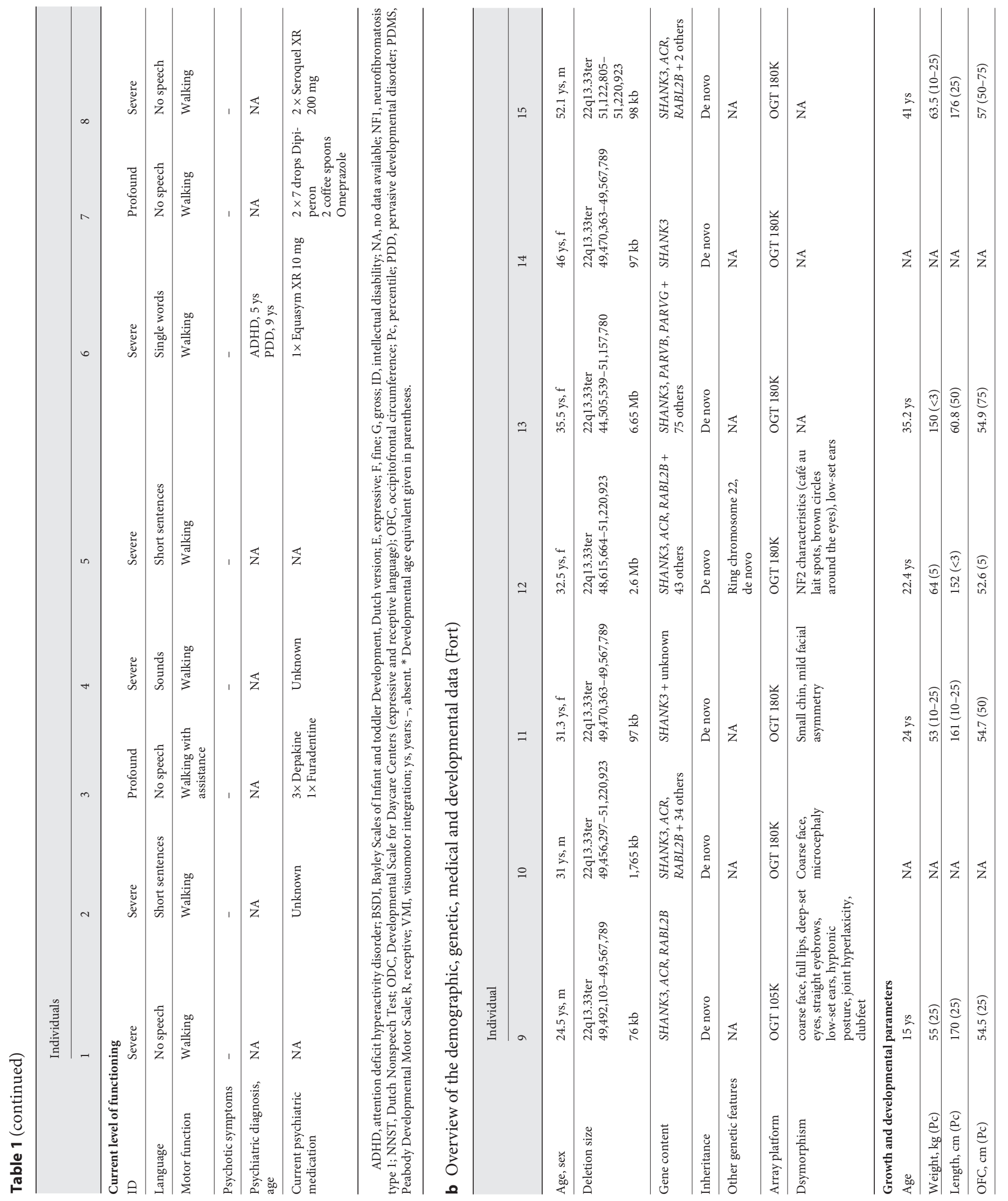




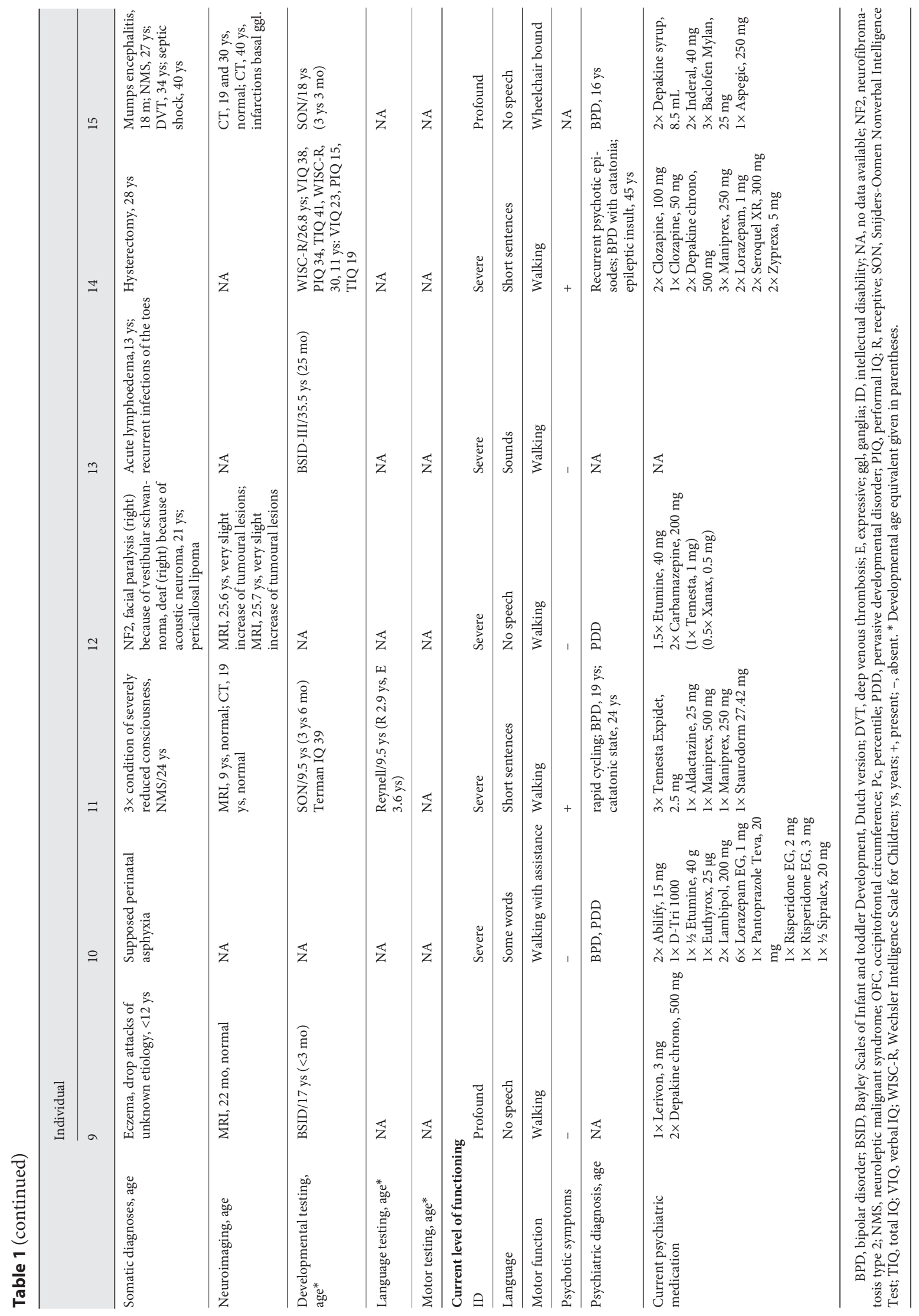


Table 2. Domains in which progress or decline is made

\begin{tabular}{|c|c|c|}
\hline Individuals & Progress & Decline \\
\hline 1 & $\begin{array}{l}\text { Gross motor function (physical therapy), cognition } \\
\text { (recognition of parents, choosing between } 2 \text { items) }\end{array}$ & - \\
\hline 2 & Vocabulary & - \\
\hline 3 & Gross motor function, attention for the environment & - \\
\hline 4 & - & Vocabulary \\
\hline 5 & Toilet training & - \\
\hline 6 & $\begin{array}{l}\text { Talking, gross motor function, more patient and at } \\
\text { ease (possibly because of medication) }\end{array}$ & - \\
\hline 7 & Gross motor function (physical therapy) & Concentration, speech \\
\hline 8 & Household chores, concentration & - \\
\hline 9 & - & - \\
\hline 10 & $\begin{array}{l}\text { Decrease in agitation/aggressiveness (possibly because } \\
\text { of medication) }\end{array}$ & $\begin{array}{l}\text { Language/vocabulary, fine and gross motor function, } \\
\text { sensory tolerance }\end{array}$ \\
\hline 11 & - & More rapid succession of BPD cycles \\
\hline 12 & Holding urine & $\begin{array}{l}\text { Adaptive functioning, functioning in group, } \\
\text { communication, activity }\end{array}$ \\
\hline 13 & - & Gross motor function, activity \\
\hline 14 & - & $\begin{array}{l}\text { Household chores, adaptive functioning, fine motor } \\
\text { function, holding urine, cognition, vocabulary }\end{array}$ \\
\hline 15 & Decrease in agitation (possibly because of medication) & Physical disability, speech \\
\hline
\end{tabular}

netic, medical, and developmental data for each individual. During the semi-structured interview, questions regarding progress or decline of several developmental and adaptive domains were asked. For many individuals with PMS, a regression in functioning over time across several domains was reported. Table 2 gives an overview of progress or decline across several domains for each individual.

The diagnosis of PMS (a deletion in the SHANK3 gene) was confirmed in all individuals with molecular cytogenetic techniques (microarray analysis using Oxford Gene Technology or Illuminate platforms) according to standard procedures. The deletion in SHANK3 was confirmed in P7 as well, but detailed information was not available. Deletion sizes on the terminal end of chromosome 22 varied from $76 \mathrm{~kb}$ to $6.65 \mathrm{Mb}$. One SHANK3 deletion was maternally inherited (P6), all others were de novo. Several individuals had other deletions or duplications besides a SHANK3 deletion (Table 1). P8 had an additional diagnosis of neurofibromatosis type 1, and P12 had an additional diagnosis of neurofibromatosis type 2 .

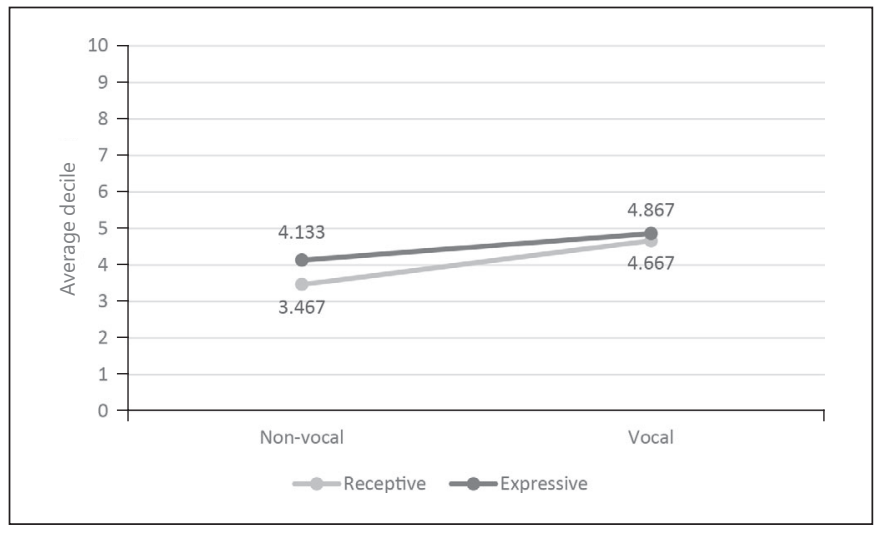

Fig. 1. Average deciles on the CPZ (Communicatieprofiel Zwakzinnigen) questionnaire.

Earlier cognitive assessments, recent administrations of the cognitive scale of BSID-III-NL and/or results on SRZ reveal that all 15 individuals function on a severe to 
Fig. 2. Visual representation of the scores on the AVZ-R (Autisme en Verwante stoornissenschaal-Z-revisie) questionnaire. ASD region (red), borderline region (yellow), and the normal region (green) are shown. $n=15$.

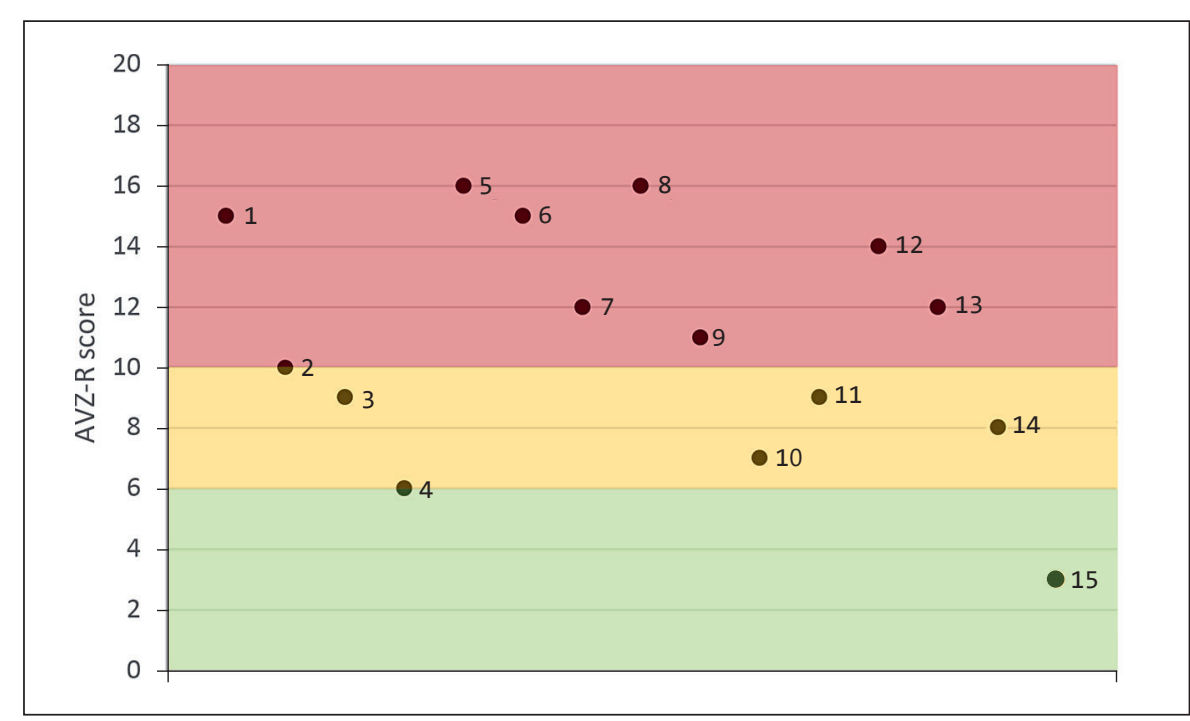

Table 3. Events causing challenging behavior

\begin{tabular}{|c|c|c|}
\hline & Individuals & $\begin{array}{l}\text { Frequency, } \\
n(\%)\end{array}$ \\
\hline Event against their will/against expectation & $1,2,5,8,11-14$ & $8(53)$ \\
\hline Physical discomfort & $3,4,7,9,15$ & $5(33)$ \\
\hline Overwhelmed by stimuli & $10,14,15$ & $3(20)$ \\
\hline Extreme excitement & 4,6 & $2(13)$ \\
\hline Difficulties understanding the situation & 4 & $1(7)$ \\
\hline
\end{tabular}

profound level of ID (Table 1). Seven individuals (46.67\%) had a total SRZ score which corresponded to a percentile lower than 10, and 9 individuals (60\%) had a daily skills score $<10$ th percentile, indicating a very low level of adaptive behaviour. Female participants scored significantly better than male participants (social orientation subscale $(U=6, z=-2.549, p=0.012, r=-0.658)$ with a total SRZ score of $U=8.5, z=-2.224, p=0.026, r=-0.574$.

Language developed slowly in all individuals, although there was variability in language and communicative ability across individuals (Table 1). On average, low deciles were retrieved for all subscales of the communication profile (Fig. 1). The participants scored remarkably lower on the subscale receptive non-vocal communication. Females attained significantly higher scores on the subscale expressive non-vocal subscale $(U=7.5, z=-2.306, p=$ $0.018, r=-0.595)$.

There was a high incidence of challenging behaviour: more than half of the participants $(53.33 \%)$ had a total emotional and behavioural problem score on VOG which corresponded to $P c$. 75 or higher. When the subscales self-absorbed behaviour and social relating were consid-

Deep Phenotyping in Phelan-McDermid Syndrome
Table 4. Coping strategies

\begin{tabular}{|c|c|c|}
\hline & Individuals & $\begin{array}{l}\text { Frequency, } \\
n(\%)\end{array}$ \\
\hline Distraction & $1,3,7,10,12,14$ & $6(40)$ \\
\hline Ignoring & $2,5,10,12,13$ & $5(33)$ \\
\hline $\begin{array}{l}\text { Time-out/separation/withdrawal } \\
\text { from the stimulus }\end{array}$ & $5,9,11,12,15$ & $5(33)$ \\
\hline Concession & $2,11,12,14$ & $4(27)$ \\
\hline Listening to music & 8,9 & $2(13)$ \\
\hline Involvement of a reassuring object & 8,9 & $2(13)$ \\
\hline Walking/going outdoors & 8,15 & $2(13)$ \\
\hline Driving in the car & 12 & $1(7)$ \\
\hline Clarifying the situation & 4 & $1(7)$ \\
\hline $\begin{array}{l}\text { Anticipation and facilitation of } \\
\text { transitions }\end{array}$ & 6 & $1(7)$ \\
\hline Bathing & 8 & $1(7)$ \\
\hline Fulfilling his/her need & 7 & $1(7)$ \\
\hline
\end{tabular}

ered, 10 individuals $(66.67 \%)$ had a score which corresponded to $P c$. 75 or higher. Individuals $<18$ years scored significantly higher on the total problem score $(U=10$, $z=-2.083, p=0.04, r=-0.538)$ and the subscale self-absorbed behaviour $(U=10.5, z=-2.031, p=0.04, r=$ $-0.524)$. Females scored only marginally significantly higher on the subscale disturbances in communication $(U=10, z=-2.016, p=0.05, r=-0.521)$. Parents and caregivers distinguished several causes of challenging behaviour (Table 3) and used a variety of coping strategies (Table 4). Because of the hypothesis that challenging behaviour may be linked to frustrations in communicative encounters (e.g., not being able to fluently say what one is wanting to say), parents or caregivers were asked for the occurrence of frustrated behaviour during communica- 
Fig. 3. Visual representation of the scores on the AVZ-R questionnaire from Denayer et al. [2012] and the present study. ASD region (red), borderline region (yellow), and the normal region (green) are shown. $n=5$.

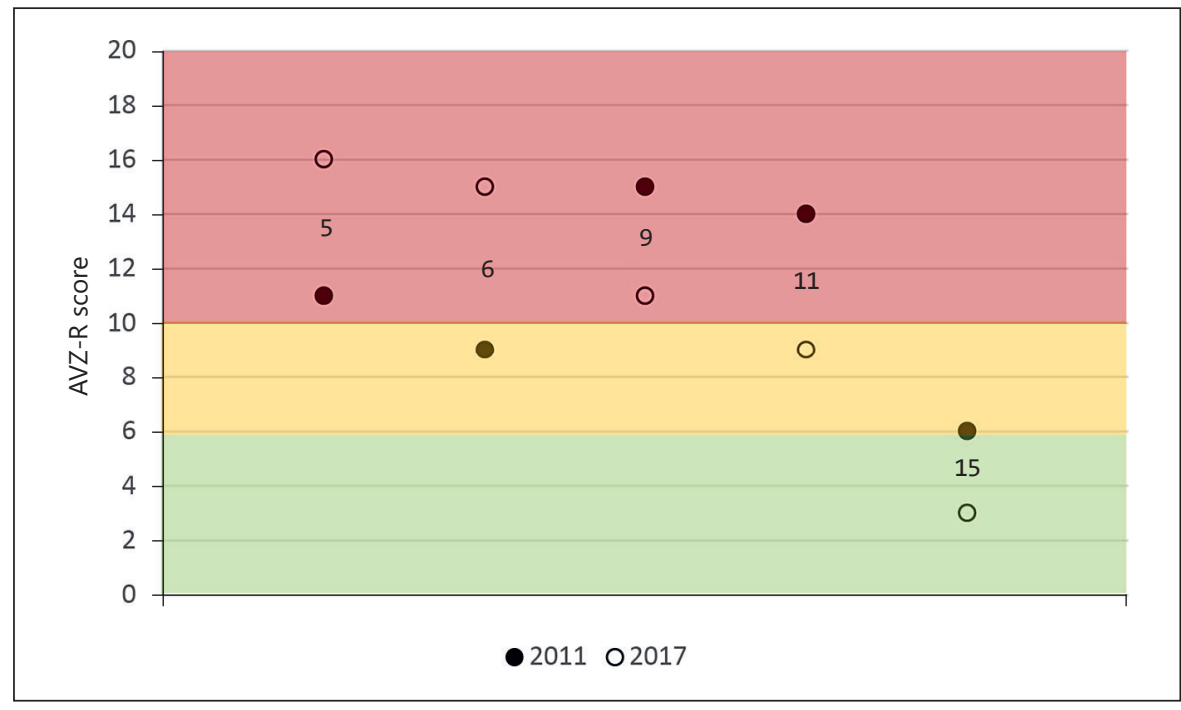

Table 5. Sensory information processing: frequencies of the assigned categories per subscale, divided by age and gender $(n=15)$

$\begin{array}{lll}\text { Age } & \text { Gender } \\ <18 & >18 & \text { female male }\end{array}$

\begin{tabular}{lllll} 
Tactile sensitivity & & & & \\
Clear difference & 4 & 3 & 5 & 2 \\
Normal & 2 & 4 & 2 & 4 \\
Supposed difference & 2 & 0 & 2 & 0 \\
\hline
\end{tabular}

\begin{tabular}{lllll}
\hline Taste/smell sensitivity & & & & \\
Normal & 8 & 7 & 9 & 6 \\
\hline
\end{tabular}

\begin{tabular}{lllll}
\hline Movement sensitivity & & & & \\
Clear difference & 2 & 4 & 5 & 1 \\
Normal & 5 & 3 & 4 & 4 \\
Supposed difference & 1 & 0 & 0 & 1 \\
\hline
\end{tabular}

\begin{tabular}{lcccc}
\hline Underresponsiveness/sensation seeking & & & \\
Clear difference & 8 & 4 & 8 & 4 \\
Normal & 0 & 3 & 1 & 2 \\
\hline
\end{tabular}

\begin{tabular}{lllll}
\hline Auditory filtering & & & & \\
Clear difference & 6 & 0 & 3 & 3 \\
Normal & 0 & 3 & 2 & 1 \\
Supposed difference (low) & 2 & 4 & 4 & 2 \\
\hline
\end{tabular}

\begin{tabular}{lllll}
\hline Low energy/weak & & & & \\
Clear difference & 5 & 3 & 6 & 2 \\
Normal & 3 & 2 & 3 & 2 \\
Supposed difference & 0 & 2 & 0 & 2 \\
\hline
\end{tabular}

\section{Visual/auditory sensitivity}

Clear difference

Normal

Supposed difference (high)

Supposed difference (low)

$\begin{array}{llll}2 & 0 & 2 & 0 \\ 3 & 5 & 4 & 4 \\ 1 & 1 & 1 & 1 \\ 2 & 1 & 2 & 1\end{array}$

tion: in only 3 individuals (P4, P5, and P6; 20\%) frustrations occurred.

Psychiatric disorders were common. Four individuals (P10, P11, P14, and P15; 26.67\%) were diagnosed with BPD, P6 was diagnosed with attention deficit and hyperactivity disorder, and 2 individuals (P11 and P14; 13.33\%) frequently had psychotic episodes. Three individuals (P6, P12, and P10; 20\%) were formally diagnosed with ASD. Features of behaviour related to ASD were present in many individuals: on AVZ-R, 9 individuals (60\%) scored within the ASD region (red), 4 individuals (26.67\%) within the borderline region (yellow), and 2 individuals (13.33\%) within the normal region (green) (Fig. 2). The profiles of the individuals with PMS on sensory information processing were variable. $80 \%$ of the individuals scored on the subscale under responsive/sensation seeking within the "clear difference" region. A significant difference was found between younger ( $<18$ years) and older individuals ( $>18$ years) with PMS for the subscale auditory filtering ( $p=0.007$; Table 5$)$.

In a subgroup of participants $(n=5 ; \mathrm{P} 5, \mathrm{P} 6, \mathrm{P} 9, \mathrm{P} 11$, and P15) data were available on the VOG and AVZ-R questionnaire from an earlier study [Denayer et al., 2012]. In this way, it was possible to compare their scores on emotional and behavioural problems and features of ASD between 2 points in time (6-year period). No significant differences between the 2 time points were found. A visual representation of the AVZ-R scores from time 1 and time 2 is provided in Figure 3: an increase of the AVZ-R score for the younger individuals (P5 and P6) was observed in contrast to a decrease for the adult individuals 
(P9, P11, and P15). Compared to time 1, two individuals were classified in another category on time 2: P6 in the ASD region, $\mathrm{P} 11$ in the borderline region.

Finally, genotype-phenotype correlations were studied. A distinction in 2 deletion groups was made: a small (76-259 kb) or large deletion size (1,765-6,652 kb). No significant differences in cognitive development, adaptive behaviour, verbal and non-verbal communication, emotional and behavioural problems, features of ASD, or sensory information processing were observed in relation to deletion size.

\section{Discussion}

The aim of the present study was to obtain a detailed phenotype of the development, communication, and behaviour of individuals with PMS by using both quantitative and qualitative methods. In addition, data from the patients' medical records were included. In a subgroup of participants, cognitive and behavioural data from a previous study were incorporated to enable a comparison over 2 points in time (longitudinal course).

All individuals with PMS in this study functioned on a severe to profound level of ID and impaired adaptive behavior which is in agreement with earlier studies [Phelan et al., 2001; Havens et al., 2004; Dhar et al., 2010; Shaw et al., 2011; Denayer et al., 2012; Phelan and McDermid, 2012; Zwanenburg et al., 2016], indicating a high level of need for support from the environment for daily functioning. Furthermore, language development was severely delayed and showed (to a different degree) deficits in all individuals, which is again congruent with earlier findings [Phelan et al., 2001; Havens et al., 2004; Manning et al., 2004; Cusmano-Ozog et al., 2007; Dhar et al., 2010; Phelan and McDermid, 2012]. Finally, $86.67 \%$ of the study group showed many characteristics of ASD [Phelan et al., 2001; Havens et al., 2004; Manning et al., 2004; Cusmano-Ozog et al., 2007; Denayer et al., 2012; Soorya et al., 2013].

Maladaptive or challenging behaviour was frequently reported in the present sample [see also Shaw et al., 2011]. From interviews and observations, it was reported that situations with elements of restriction, unexpectedness, or undesirableness act as risk factors for challenging behaviour. To cope with this challenging behaviour, parents frequently mentioned the use of strategies such as distraction, ignoring, withdrawal from the stimulus, or concession. Furthermore, regarding sensory processing, for $80 \%$ of the individuals, there is a strong indication for a high sensory threshold and an active or passive strategy to-

Deep Phenotyping in Phelan-McDermid Syndrome wards sensory events [Dunn, 2001]. These individuals may seek (or produce) stimulation and may seem active and excitable (active strategy) [Dunn, 2001]. In PMS, exemplary behaviour of self-stimulation includes teeth grinding, rocking, or mouthing [Phelan and McDermid, 2012]. On the other hand, individuals may seem disconnected, requiring intense stimuli and explicit directives (passive strategy) [Dunn, 2001]. As an example, often a decreased perception of pain is observed in PMS [Phelan and McDermid, 2012].

Age seemed to play a role in the behavioural phenotype of the present sample of participants. Younger individuals exhibited more emotional and behavioural problems, presented features of ASD more frequently, had more difficulties with auditory filtering, and can still make progress (even though sometimes limited, restricted to gross motor function and because of intensive physical therapy) as reported by their parents or caregivers. In adults with PMS, more often a decline in domains such as language (use of words), motor function (fine and gross), adaptive behaviour, activity, and sensory tolerance was reported and observed. Regression in individuals with PMS has previously been reported [Bonaglia et al., 2011; Denayer et al., 2012; Soorya et al., 2013; Serret et al., 2015; Egger et al., 2016; Reierson et al., 2017]. Longitudinal data (6-year time period) for a subgroup of individuals with PMS ( $n=$ 5) revealed no statistically significant changes regarding emotional and behavioural problems as well as presence of ASD features. However, for the younger individuals $(<18$ years), an increase in features of ASD was observed over time while a decrease was observed in the older individuals ( $>18$ years). An explanation could be that with increasing age, features of ASD might become less prominent in persons with PMS due to other factors such as a diagnosis of BPD or increased physical impairment.

The role of gender on the several developmental and adaptive domains in PMS was less clear in the present sample. Female participants appeared to have more developed adaptive skills - in contrast to a study by Zwanenburg et al. [2016] - and were more proficient in one aspect of communication (non-verbal expressive communication). However, they showed more "communication disorders." These disturbances in communication included inadequate communication, and sometimes showed features of ASD (e.g., arranging objects in a constant order or keeping a constant routine) or psychosis (e.g., talking to oneself).

In contrast to other studies, no significant differences in functioning between persons with a smaller or greater deletion size were found. Some individuals with a 
smaller deletion size even had a more severe phenotype than some individuals with a larger deletion (e.g., P2 and P13, Table 1). Furthermore, several individuals with PMS in our sample had other CNVs in addition to a SHANK3 deletion. Therefore, as already indicated by Sarasua et al. [2014] and Tabet et al. [2017], it is likely that the deletion size, the specific region of $22 \mathrm{q} 13$, and other CNVs contribute altogether to the phenotypic expression of PMS.

\section{Strengths and Limitations of the Present Study}

This study aimed at mapping the developmental and behavioural phenotype of individuals with PMS. Several aspects of the phenotype were explored and described in detail, providing a differentiated and informative phenotype of a group of individuals with PMS.

Concerning the methods, several strengths could be noticed: (1) an $83.33 \%$ response rate for participation was reached, (2) both quantitative (questionnaires) and qualitative methods (interview and observation) were combined to add more details to the data, (3) a multi-informant approach (parents and caregivers) was employed, and (4) longitudinal data were available for a subgroup $(30 \%)$ of the study sample.

The present study also has several limitations: (1) due to the rarity of PMS, a relatively small sample has been studied. Data were not normally distributed, so descriptive and non-parametric statistical methods had to be used, which may have an impact on the statistical power; (2) other CNVs, co-morbid psychiatric diagnosis such as $\mathrm{BPD}$ and recurrent psychotic episodes as well as tumours because of neurofibromatosis type 2 (which may lead to physical discomfort) could all contribute to possible distortions in the general picture of the development, communication and behaviour of individuals with PMS; (3) mainly indirect measures were used. The current findings need to be confirmed by direct methods in order to be able to draw more certain conclusions; (4) several questionnaires were outdated. The choice for the SRZ, CP-Z and AVZ-R was made, nonetheless, because of the availability of norms for people with severe-profound ID, user-friendliness, and short administration time. In future research, the use of alternative, recent instruments such as the Adaptive Behaviour Assessment System [Harrison and Oakland, 2015], the Communication Matrix (http:// communicationmatrix.org), or the Autism Diagnostic and Observation Schedule [Lord et al., 2012] is preferred, and (5) due to a broad age range of the participants, it was not possible with every questionnaire to choose the right norm group for each individual. In each individual case, the most appropriate norm group was chosen, but results should be interpreted carefully.

One of the participants, P6, inherited the deletion maternally. Tabet et al. [2017] described an inherited SHANK3 deletion transmitted by a mother without ID and ASD to 5 daughters. The mother from the present sample works in a sheltered environment and has moderate ID. To the best of our knowledge, this has not been previously described. Unfortunately, the mother could not be included in the present study because of familial reasons.

\section{Recommendations for Practice and Directions for \\ Future Research}

Because of the complex phenotype (medical, behavioural, and psychiatric) in many individuals with PMS, thorough multidisciplinary care and follow-up is needed. Furthermore, a good balance between the developmental/adaptive abilities and limitations of the person with PMS as well as the environmental demands is essential to ensure the individual's wellbeing.

Future multicentre studies are needed to explore the impact of and coping with challenging behaviour, sensory information processing, and psychiatric disorders as well as possible age and gender effects. Finally, it is crucial to follow individuals with PMS longitudinally to gain more insight in their changing needs and developmental trajectories regarding communication, cognition, behaviour, and (neuro)motor function over time.

\section{Acknowledgements}

We would like to thank the patients and their families, the staff and caregivers of the schools and institutions for their kindness, flexibility, and helpful cooperation. We would also like to thank the members and staff of the Belgian patient association NPO $22 \mathrm{q} 13$ for their cooperation and warm interest in the study.

\section{Statement of Ethics}

The research protocol was approved by the Ethics Committee of the University Hospitals Leuven prior to the study. The study was explained extensively to the parents and caregivers of the patients. All parents and legal representatives gave written informed consent.

\section{Disclosure Statement}

The authors have no conflicts of interest to declare. 


\section{Funding Sources}

This study was funded by the Phelan-McDermid syndrome research fund KU Leuven and the Belgian patient association NPO $22 \mathrm{q} 13$.

\section{Author Contributions}

This study was performed in the context of an internship and under supervision of the senior authors.

\section{References}

Bayley N: Bayley Scales of Infant and Toddler Development, 3rd ed (Pearson, Amsterdam 2015).

-Boeckers T, Bockmann J, Kreutz M, Gundelfinger E: ProSAP/Shank proteins - a family of higher order organizing molecules of the postsynaptic density with an emerging role in human neurological disease. J Neurochem 81:903910 (2002).

Bonaglia M, Giorda R, Borgatti R, Felisari G, Gagliardi C, et al: Disruption of the ProSAP2 gene in a $\mathrm{t}(12 ; 22)(\mathrm{q} 24.1 ; \mathrm{q} 13.3)$ is associated with the 22q13.3 deletion syndrome. Am J Hum Genet 69:261-268 (2001).

-Bonaglia M, Giorda R, Beri S, De Agostinil C, Novara $\mathrm{F}$, et al: Molecular mechanisms generating and stabilizing terminal 22q13 deletions in 44 subjects with Phelan-McDermid syndrome. PLoS Genet 7:e1002173 (2011).

-Cusmano-Ozog K, Manning M, Hoyme $\mathrm{H}$ : 22q13.3 deletion syndrome: a recognizable malformation syndrome associated with marked speech and language delay. Am J Med Genet C Semin Med Genet 145C:393-398 (2007).

Delhaye A, Toutain A, Aboura A, Dupont C, Tabet AC, et al: Chromosome 22q13.3 deletion syndrome with a de novo interstitial 22q13.3 cryptic deletion disrupting SHANK3. Eur J Med Genet 52:328-332 (2009).

Denayer A, Van Esch H, de Ravel T, Frijns JP, Van Buggenhout G, et al: Neuropsychopathology in 7 patients with the 22q13.3 deletion syndrome: presence of bipolar disorder and progressive loss of skills. Mol Syndromol 3:14-20 (2012).

- Dhar S, del Gaudio D, German J, Peters S, Ou Z, et al: 22q13.3 deletion syndrome: clinical and molecular analysis using array CGH. Am J Med Genet A 152A:573-581 (2010).

Disciglio V, Lo Rizzo C, Mencarelli M, Mucciolo M, Marozza A, et al: Interstitial 22q13 deletions not involving SHANK3 gene: a new contiguous gene syndrome. Am J Med Genet A 164A:1666-1676 (2014)

Dunn W: The sensations of everyday life: empirical, theoretical, and pragmatic considerations. Am J Occup Ther 55:608-620 (2001).

Dunn W: Sensory Profile (herziene druk) (Pearson Assessment and Information, Amsterdam 2013)
Egger J, Zwanenburg R, van Ravenswaaij-Arts C, Kleefstra T, Verhoeven, W: Neuropsychological phenotype and psychopathology in seven adult patients with Phelan-McDermid syndrome: implications for treatment strategy. Genes Brain Behav 15:395-404 (2016).

Harrison P, Oakland T: Adaptive Behavior Assessment System (ABAS-3-NL), 3rd ed [Manual] (Western Psychological Services, Torrance 2015).

Havens JM, Visootsak J, Phelan MC, Graham JM Jr: 22q13 deletion syndrome: an update and review for the primary pediatrician. Clin $\mathrm{Pe}$ diatr (Phila) 43:43-53 (2004).

Kolevzon A, Angarita B, Bush L, Wang A, Frank $Y$, et al: Phelan-McDermid syndrome: a review of the literature and practice parameters for medical assessment and monitoring. J Neurodev Disord 6:39 (2014).

Koot HM, Dekker MC: Handleiding voor de VOG (Erasmus MC, Rotterdam 2001).

Kraijer DW: Autisme- en Verwante stoornissenschaal-Z-Revisie. (Swets \& Zeitlinger, Leiden 1999).

Kraijer DW, Kema GN: Schalen voor Zwakzinnigen. (Swets \& Zeitlinger, Leiden 1981).

Lord C, Luyster R, Gotham K, Guthrie W: (2012). Autism diagnostic observation schedule, 2nd ed (ADOS-2) manual (Part II), Toddler module (Western Psychological Services, Torrance 2012).

Luciani J, de Mas P, Depetris D, Mignon-Ravix C, Bottani A, et al: Telomeric 22q13 deletions resulting from rings, simple deletions, and translocations: cytogenetic, molecular, and clinical analyses of 32 new observations. J Med Genet 40:690-696 (2003).

Manning MA, Cassidy SB, Clericuzio C, Cherry AM, Schwartz S, et al: Terminal 22q deletion syndrome: a newly recognized cause of speech and language disability in the autism spectrum. Pediatrics 114:451-457 (2004).

Misceo D, Rødningen O, Barøy T, Sorte H, Mellembakken J, et al: A translocation between $\mathrm{Xq} 21.33$ and 22q13.33 causes an intragenic SHANK3 deletion in a woman with PhelanMcDermid syndrome and hypergonadotropic hypogonadism. Am J Med Genet A 155A:403-408 (2011).

- Oberman L, Boccuto L, Cascio L, Sarasua S, Kaufmann W: Autism spectrum disorder in Phelan-McDermid syndrome: initial characterization and genotype-phenotype correlations. Orphanet J Rare Dis 10:105 (2015).
Phelan K, McDermid H: The 22q13.3 deletion syndrome (Phelan-McDermid Syndrome). Mol Syndromol 2:186-201 (2012).

- Phelan MC, Rogers CR, Saul RA, Stapleton GA, Sweet K, et al: 22q13 deletion syndrome. Am J Med Genet 101:91-99 (2001).

-Reierson G, Bernstein J, Froehlich-Santino W, Urban A, Purmann C, et al: Characterizing regression in Pehaln McDermid Syndrome (22q13 deletion syndrome). J Psychiatr Res 91:139-144 (2017)

- Sarasua S, Dwivedi A, Boccuto L, Chen CF, Sharp $\mathrm{J}$, et al: 22q13.2q13.32 genomic regions associated with severity of speech delay, developmental delay, and physical features in Phelan-McDermid syndrome. Genet Med 16: 318-328 (2014).

-Serret S, Thümmler S, Dor E, Vesperini S, Santos A, Askenazy F: Lithium as a rescue therapy for regression and catatonia features in two SHANK3 patients with autism spectrum disorder: case reports. BMC Psychiatry 15:107 (2015).

- Shaw SR, Rahman A, Sharma A: Behavioral profiles in Phelan-McDermid syndrome: focus on mental health. J Ment Health Res In 4:1-18 (2011).

Soorya L, Kolevzon A, Zweifach J, Lim T, Dobry $\mathrm{Y}$, et al: Prospective investigation of autism and genotype-phenotype correlations in 22q13 deletion syndrome and SHANK3 deficiency. Mol Autism 4:18 (2013).

Tabet A, Rolland T, Ducloy M, Lévy J, Buratti J, et al: A framework to identify contributing genes in patients with Phelan-McDermid syndrome. NPJ Genom Med 2:32 (2017).

Van Baar AL, Steenis LJ, Verhoeven M, Hessen DJ: Bayley-III-NL. Technische Handleiding. (Pearson Assessment and Information B.V., Amsterdam 2014).

Willems J, Verpoorten R: CommunicatieProfiel-Z: Handleiding. (Swets \& Zeitlinger, Lisse 1996).

-Wilson H, Wong A, Shaw S, Tse WY, Stapleton G, et al: Molecular characterisation of the 22q13 deletion syndrome supports the role of haploinsufficiency of SHANK3/PROSAP2 in the major neurological symptoms. J Med Genet 40:575-584 (2003).

Zwanenburg RJ, Ruiter SA, van den Heuvel ER, Flapper BC, Van Ravenswaaij-Arts CM: Developmental phenotype in Phelan-McDermid (22q13.3 deletion) syndrome: a systematic and prospective study in 34 children. J Neurodev Disord 8:16 (2016). 